\title{
Cultivares de trigo sob manejos de solo e água, na região de cerrado
}

\author{
Wheat cultivars under soil and water management strategies, in the cerrado region
}

\author{
Marcelo Romero Ramos da Silva' Orivaldo Arf ${ }^{\text {II }}$ Ricardo Antonio Ferreira Rodrigues ${ }^{\text {III }}$
}

\section{RESUMO}

A cultura do trigo, sob irrigação por aspersão ou sequeiro, vem sendo introduzida nos últimos anos no cerrado brasileiro. O objetivo do trabalho foi avaliar o efeito do manejo do solo e água nas características fenológicas e produtivas de cultivares de trigo, na região de cerrado. O estudo foi conduzido na área experimental da UNESP, localizada em Selvíria, MS. Adotou-se um delineamento experimental em blocos casualizados, num esquema fatorial, com quatro repetições, sendo as mesmas constituídas por dois manejos de solo (arado de aivecas e plantio direto), dois manejos de água (-0,05MPa e-0,07MPa) e três cultivares de trigo ("BRS 210", "BR 18", "IAC 24”). O plantio direto proporcionou maior rendimento de grãos de trigo em relação ao preparo do solo com arado de aivecas para as cultivares "BRS 210" e "BRS 18". O manejo de água com tensão -0,05MPa foi o que proporcionou maior rendimento de grãos.

Palavras-chave: Triticum aestivum L., plantio direto, arado de aivecas, tensão de água no solo.

\section{ABSTRACT}

The culture of wheat, under sprinkler irrigation or dry land, has been introduced in recent years in the cerrado region of Brazil. This research was developed with the objective of evaluating the effects of tillage methods and water management strategies on phenological and productive characteristics of wheat cultivars, in the cerrado region. The research reported here was developed at the UNESP experiment station, in Selvíria state of Mato Grosso do Sul, Brazil. A randomized block design with a factorial arrangement of treatments $(2 \times 2 \times 3)$, with four repetitions, constituted by two tillage methods (moldboard plow and no-tillage), two water management strategies (-0.05MPa and -0.07MPa) and three wheat cultivars ('BRS 210', 'BR 18', 'IAC 24'). The no-tillage allowed higher grain yield in relation to soil tillage with moldboard plow, to the wheat cultivars 'BRS 210'e 'BRS 18'. The water management strategy $-0.05 \mathrm{MPa}$ was the best wheat yield.

Key words: Triticum aestivum L., no-tillage, mold-board plow, tension of water on soil.

\section{INTRODUÇÃO}

O trigo é um dos cereais mais utilizados na alimentação humana, sendo o Brasil um grande consumidor, destacando-se pela parcial dependência da importação. É um cereal básico, cultivado em diferentes condições ambientais, desde a Argentina até a Finlândia, o que exige trabalhos intensos de seleção, visando a adaptação da cultura ao ambiente de cultivo (KLAR \& DENADAI, 1996 e FUMIS et al., 1997).

Com o crescimento do consumo de trigo, houve aumento da produção em regiões agrícolas nãotradicionais. Dessa forma, o trigo foi introduzido em áreas originalmente ocupadas com vegetação de cerrado, ocorrendo, no início, problemas de adaptação das cultivares. Com isso, surgiu a necessidade de informações quanto ao manejo adequado do solo e da água para estas regiões, possibilitando o aumento da produtividade da cultura (SOUZA, 2003).

Dentre os preparos do solo, o realizado com arado de aivecas proporciona aumento na aeração e desestruturação do solo. Entretanto, diminui a compactação da camada superficial e retenção de água

\footnotetext{
IPrograma de Pós-graduação em Agronomia, Universidade Estadual Paulista (UNESP), Ilha Solteira, SP, Brasil.

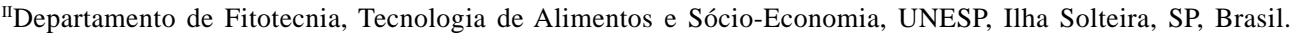

IIIDepartamento de Fitossanidade, Engenharia Rural e Solos, Agronomia, UNESP. Av. Brasil, Centro, 56, 15385-000, Ilha Solteira,

SP, Brasil. E-mail: ricardo@agr.feis.unesp.br. Autor para correspondência.
} 
(FREITAS, 1992; VIEIRA, 1985). O plantio direto proporciona aumento da retenção de água e acúmulo de matéria orgânica, o que mantém a superfície do solo coberta de resíduos vegetais, dificultando a germinação de plantas invasoras (ALBUQUERQUE et al., 1995; VIEIRA et al., 1978; ABRÃO et al., 1979).

Além da importância do preparo do solo, o fornecimento de quantidades adequadas de água favorece $\mathrm{o}$ aumento da produtividade do trigo. GUERRA et al. (1994) recomendam para a cultura do trigo que a irrigação deva iniciar-se quando a tensão de água no solo atingir valores em torno de $-0,06 \mathrm{MPa}$, para a profundidade de $0,10 \mathrm{~m}$.

Este trabalho objetivou avaliar o efeito do preparo do solo e manejo da água nas características fenológicas e produtivas de cultivares de trigo, cultivadas em solo originalmente com vegetação de cerrado.

\section{MATERIAL E MÉTODOS}

O experimento foi conduzido na área experimental da UNESP, município de Selvíria - MS, com as seguintes coordenadas geográficas: $20^{\circ} 22^{\prime} \mathrm{S}$; $51^{\circ} 22^{\prime}$ 'W e altitude média de 335 metros.

O solo foi classificado (DEMATTÊ, 1980; SOUZA, 2000) como Latossolo Vermelho Distrófico típico argiloso, A moderado, hipodistrófico, álico, caulinítico, férrico, compactado, muito profundo, moderadamente ácido (LVd). A composição granulométrica do solo é composta por argila, $450 \mathrm{~g} \mathrm{~kg}^{-1}$; silte, $20 \mathrm{~g} \mathrm{~kg}^{-1}$; areia fina, $370 \mathrm{~g} \mathrm{~kg}^{-1}$; areia grossa, $160 \mathrm{~g}$ $\mathrm{kg}^{-1}$ e areia total, $530 \mathrm{~g} \mathrm{~kg}^{-1}$.

O delineamento experimental foi em blocos casualizados no esquema fatorial $3 \times 2 \times 2$, com quatro repetições. Os tratamentos consistiram de três cultivares ("BRS 210", "BR 18”, “IAC 24”), dois preparos do solo (arado de aivecas e plantio direto) e dois manejos da água (-0,05MPa e-0,07MPa). As parcelas possuíam nove linhas de $6 \mathrm{~m}$ de comprimento, espaçadas $0,17 \mathrm{~m}$ entre si, com área total de $9,18 \mathrm{~m}^{2}$, sendo consideradas como área útil as sete linhas centrais, eliminando-se $0,5 \mathrm{~m}$ de suas extremidades.

Para o tratamento com mobilização total do solo, a operação foi realizada com arado de aivecas, seguida de duas gradagens (grade leve), sendo a primeira após a mobilização inicial do solo e a segunda às vésperas da semeadura, isso para facilitar esta operação e o controle de plantas invasoras. Na área de plantio direto, implantada desde 1998, a cultura anterior foi a de arroz. A dessecação da cobertura vegetal foi realizada com aplicação de gliphosate (1.560 ha $^{-1}$ do i.a).
As características químicas do solo foram determinadas, para a camada de $0,0-0,20 \mathrm{~m}$, antes da instalação do experimento, segundo metodologia proposta por RAIJ \& QUAGGIO (1983), e apresentaram os seguintes resultados, respectivamente, para a área com arado de aivecas e plantio direto: $\mathrm{P}$ (resina), $15 \mathrm{e}$ $36 \mathrm{mg} \mathrm{dm}^{-3}$; M.O., 20 e 22mg dm${ }^{-3}$; $\mathrm{pH}\left(\mathrm{CaCl}_{2}\right), 5,2$ e 4,8; $\mathrm{K}^{+}, 1,9 \mathrm{e} 4,0 \mathrm{mmol}_{\mathrm{c}} \mathrm{dm}^{-3} ; \mathrm{Ca}^{++}, 25$ e $24 \mathrm{mmol}_{\mathrm{c}} \mathrm{dm}^{-3} ; \mathrm{Mg}^{++}$, 15 e $14 \mathrm{mmol}_{\mathrm{c}} \mathrm{dm}^{-3} \mathrm{e} \mathrm{V}, 63$ e $53 \%$.

Utilizou-se uma semeadora/adubadora com a finalidade de distribuir o adubo e abrir o sulco para posterior semeadura manual. Esse procedimento foi realizado tanto para o manejo com arado de aivecas como para o plantio direto. A densidade de semeadura foi de 80 sementes por metro, tratadas com thiodicarb (525g de i.a./100kg de sementes), sendo as sementes cobertas com uma camada de solo de aproximadamente $0,05 \mathrm{~m}$. Após a semeadura, foi realizada a aplicação do herbicida pré-emergente pendimethalin $\left(1750 \mathrm{~g} \mathrm{ha}^{-1} \mathrm{de}\right.$ i.a.) e de bentazon ( $720 \mathrm{~g} \mathrm{ha}^{-1}$ de i.a) aos 25 dias após a emergência das plantas.

A adubação básica na semeadura foi efetuada de acordo com recomendações para a cultura de trigo e análise de solo, sendo utilizados $210 \mathrm{~kg} \mathrm{ha}^{-1}$ da formulação 8-28-16. Após 30 dias da emergência do trigo, efetuou-se a adubação de cobertura com $90 \mathrm{~kg}$ ha ${ }^{-1}$ de N.

Foram instaladas 12 baterias de tensiômetros de mercúrio, sendo seis no manejo com arado de aivecas e seis no plantio direto. Cada bateria foi composta por dois tensiômetros, sendo um confeccionado para monitorar o potencial da água no solo a $0,10 \mathrm{~m}$ e o outro para $0,20 \mathrm{~m}$. As baterias foram instaladas aleatoriamente na área útil das parcelas, realizando-se diariamente leituras da altura da coluna de mercúrio. As irrigações foram realizadas quando a média das leituras nas baterias indicava valor do potencial da água no solo de -0,07MPa (denominada de lâmina 1 ou L1) e de -0,05MPa (denominada de lâmina 2 ou L2).

A quantidade de água a ser reposta ao solo foi calculada pela expressão QAR $=(\mathrm{CC}-\mathrm{UI}) * 1000 * \mathrm{z}$, sendo QAR a lâmina de água a ser reposta (mm); CC a capacidade de campo $\left(\mathrm{m}^{3} \mathrm{~m}^{-3}\right)$; UI a teor de água no solo no momento da irrigação $\left(\mathrm{m}^{3} \mathrm{~m}^{-3}\right)$ e z a profundidade efetiva do sistema radicular da cultura (m), sendo de $0,20 \mathrm{~m}$.

Todos os dados foram avaliados por meio da análise de variância pelo teste $F$, sendo significativo a $5 \%$ de probabilidade, aplicando-se o teste de Tukey para comparação das médias. 


\section{RESULTADOS E DISCUSSÃO}

A distribuição e a quantidade das lâminas de água e precipitação durante o desenvolvimento da cultura do trigo (Figura 1) resultaram em lâminas de $302 \mathrm{~mm}$ e $352 \mathrm{~mm}$, respectivamente, para L1 (-0,07MPa) e L2 (-0,05MPa), com total das precipitações ocorridas de 68mm. FARIA\& OLITTA(1987) obtiveram com trigo irrigado, em estudo conduzido em outras condições ambientais, rendimentos de $2.839 \mathrm{~kg} \mathrm{ha}^{-1} \mathrm{e} 3.019 \mathrm{~kg} \mathrm{ha}^{-1}$, respectivamente, com lâminas totais de água (irrigação+ precipitação) de $150 \mathrm{~mm}$ e $200 \mathrm{~mm}$.

Aos cultivares de trigo apresentaram diferença no número de dias para o florescimento pleno e ciclo. A cultivar "IAC 24" apresentou florescimento pleno com 70 DAE (dias após emergência) e ciclo de 120 DAE. A cultivar "BRS 210" floresceu aos 65 DAE e apresentou ciclo de 115 DAE e, para a "BR 18", o florescimento pleno foi com $60 \mathrm{DAE}$ e seu ciclo foi de $112 \mathrm{DAE}$.

Verificou-se que, para a estatura de plantas de trigo (Tabela 1), houve influência de todas as causas de variação e interação do manejo do solo (M) x lâmina de água (L). A cultivar "BR 18" apresentou a maior estatura de plantas quando comparada a "IAC 24" e a "BRS 210" (Tabela 1). Essa diferença é devida à característica da cultivar "BR 18”, a qual pode chegar a 0,75m de estatura (SOUZA, 2002).
Com os valores da estatura de plantas, na interação manejo do solo x lâmina de água (Tabela 2A), e considerando-se manejo do solo dentro de lâmina, observa-se diferença apenas para L1 (-0,07MPa), onde o plantio direto proporcionou maior estatura de planta. Para a lâmina dentro de manejo, L2 (-0,05MPa) proporcionou maior valor para ambos os manejos do solo. Nos manejos com mobilização do solo, ocorre a destruição de agregados, diminuindo a densidade do solo, o armazenamento de água e o teor de matéria orgânica, quando em comparação com a camada sem revolvimento (VIEIRA, 1991; STONE \& MOREIRA, 2000), o que ocasiona maior estatura de plantas de trigo nos tratamentos com maior disponibilidade de água no solo, concordando com FARIA \& OLITTA (1987) eGUERRA (1995).

A cultivar "BR 18" apresentou maior acamamento em relação às cultivares "IAC 24" e "BRS 210", e, para o manejo de solo, o plantio direto foi superior (Tabela 1). O plantio direto em relação ao preparo com arado de aivecas, ao longo do tempo, resulta em maiores incrementos no teor de matéria orgânica na camada superficial do solo, maior retenção de água, proporcionando maior crescimento da cultura e possível acamamento (CANNEL \& FINNEY, 1973; LAL, 1975).

Entre cultivares, houve diferença significativa para número de colmos por metro

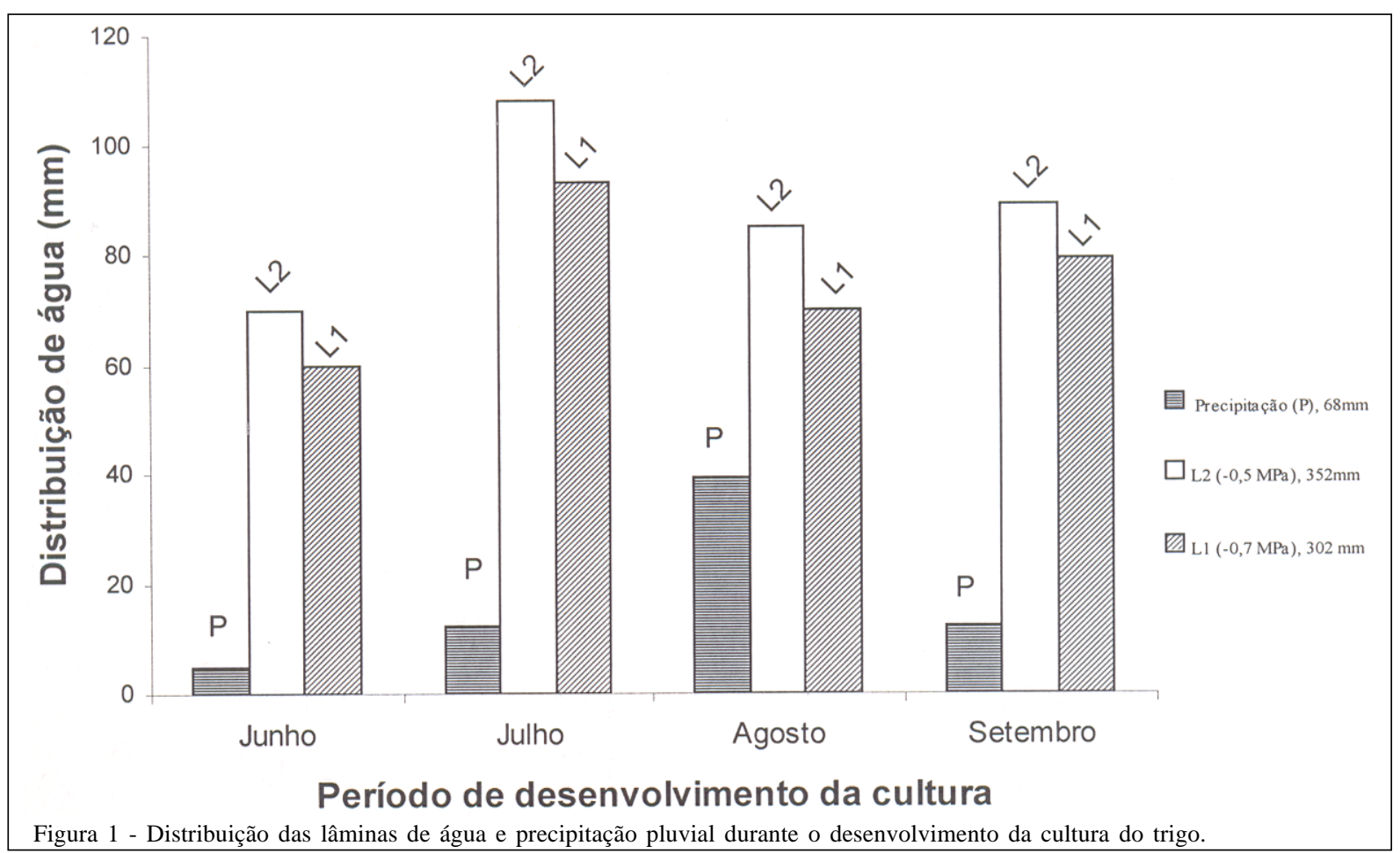

Ciência Rural, v.38, n.4, jul, 2008. 
Tabela 1 - Estatura de plantas, acamamento, número de colmos por metro quadrado e número de espigas por metro quadrado na cultura do trigo, em função de cultivar, manejo do solo e lâmina de água.

\begin{tabular}{|c|c|c|c|c|c|}
\hline \multicolumn{2}{|c|}{ Tratamentos } & \multirow{2}{*}{$\begin{array}{l}\begin{array}{l}\text { Estatura de plantas }^{[1]} \\
(\mathrm{m})\end{array} \\
0,65 \mathrm{~b}\end{array}$} & \multirow{2}{*}{$\begin{array}{c}\underset{[1][2]}{\text { Acamamento (notas) }} \\
2,93 \mathrm{~b}\end{array}$} & \multirow{2}{*}{$\begin{array}{c}\text { Número de colmos } \\
\text { por metro quadrado }{ }^{[1]}\end{array}$} & \multirow{2}{*}{$\begin{array}{c}\text { Número de espigas } \\
\text { por metro } \\
\text { quadrado }^{[1]}\end{array}$} \\
\hline \multirow{3}{*}{ Cultivar } & “IAC 24” & & & & \\
\hline & “BRS 210” & $0,65 \mathrm{~b}$ & $2,50 \mathrm{~b}$ & 503 a & 423 a \\
\hline & “BR 18” & $0,72 \mathrm{a}$ & 3,87 a & $404 \mathrm{~b}$ & 327 b \\
\hline \multirow{2}{*}{ Manejo do solo } & Arado de aivecas & $0,66 \mathrm{~b}$ & $1,75 \mathrm{~b}$ & 468 a & 381 a \\
\hline & plantio direto & 0,69 a & $2,45 \mathrm{a}$ & $449 \mathrm{a}$ & 394 a \\
\hline \multirow{2}{*}{ Lâmina de água } & L1 (-0,07 MPa) & $0,65 \mathrm{~b}$ & 2,29 a & 470 a & 376 a \\
\hline & L2 (-0,05 MPa) & $0,70 \mathrm{a}$ & $1,91 \mathrm{a}$ & 447 a & 399 а \\
\hline \multirow{6}{*}{$F^{[3]}$} & Cultivar (C) & $20,46^{* *}$ & $15,01^{* *}$ & $4,19^{* *}$ & $13,02^{* *}$ \\
\hline & Manejo do solo (M) & $7,83^{* *}$ & $11,44^{* *}$ & $0,49 \mathrm{~ns}$ & $0,66 \mathrm{~ns}$ \\
\hline & Lâmina de água (L) & $22,79^{* *}$ & $3,20 \mathrm{~ns}$ & $0,68 \mathrm{~ns}$ & $1,94 \mathrm{~ns}$ \\
\hline & $(\mathrm{C} \times \mathrm{M})$ & $0,79 \mathrm{~ns}$ & $0,03 \mathrm{~ns}$ & 0,03ns & $0,78 \mathrm{~ns}$ \\
\hline & $(\mathrm{C} \times \mathrm{L})$ & $0,43 \mathrm{~ns}$ & 3,20ns & $1,87 \mathrm{~ns}$ & $0,44 \mathrm{~ns}$ \\
\hline & $(\mathrm{M} \times \mathrm{L})$ & $4,23^{*}$ & 0,99ns & $0,08 \mathrm{~ns}$ & $0,12 \mathrm{~ns}$ \\
\hline CV\% & & 5 & 34 & 21 & 15 \\
\hline
\end{tabular}

${ }^{[1]}$ Médias seguidas da mesma letra, na coluna e para cada fator, não diferem estatisticamente entre si pelo teste de Tukey a $5 \%$ de probabilidade. ${ }^{[2]}$ Escalas de notas para acamamento: 0 - sem acamamento; 1 - 1 a $5 \%$ de plantas acamadas; 2 - 5 a $25 \%$ de plantas acamadas; 3 - 25 a 50\% de plantas acamadas; $4-50$ a $75 \%$ de plantas acamadas; 5 - 75 a $100 \%$ de plantas acamadas. ${ }^{[3]}{ }^{* * *}$, e ns são, respectivamente, significativo a $1 \%, 5 \%$ e não-significativo pelo teste $\mathrm{F}$.

quadrado (Tabela 1), em que a cultivar "BRS 210” foi superior à "BR 18”, não diferindo estatisticamente da "IAC 24". Já para manejo do solo e lâmina de água, não houve diferenças entre os tratamentos.

Para o número de espigas por metro quadrado, as cultivares "IAC 24" e "BRS 210" foram superiores à "BR 18" (Tabela 3); mas não houve diferenças para o manejo do solo e lâmina de água.

Quanto ao número de grãos por espiga, houve efeito significativo da lâmina de água e interação manejo x lâmina (Tabela 3). No desdobramento da interação manejo do solo x lâmina de água (Tabela 4A) e para os valores de manejo do solo dentro de lâmina, verifica-se que houve efeito significativo para a lâmina

Tabela 2 - Interação entre causas de variação ${ }^{[1]}$ para os componentes vegetativos.

\begin{tabular}{lcc}
\hline \multicolumn{3}{c}{ A)Efeito da interação manejo do solo e lâmina de água, para } \\
& estatura de plantas \\
\hline Manejo do solo & ------- Lâmina de água-------- \\
& L1(-0,07 MPa) & L2 (-0,05 MPa) \\
Arado de aivecas & $0,62 \mathrm{bB}$ & $0,69 \mathrm{aA}$ \\
Plantio direto & $0,67 \mathrm{aB}$ & $0,70 \mathrm{aA}$ \\
\hline
\end{tabular}

${ }^{[1]}$ Médias seguidas da mesma letra, minúscula na coluna e maiúscula na linha, para cada fator, não diferem entre si pelo teste de Tukey a 5\% de probabilidade.
L1(-0,07MPa), onde o plantio direto proporcionou maior número de grãos por espiga. Considerando lâmina de água dentro de manejo, houve efeito apenas para o arado de aivecas, onde a L2 (-0,05MPa) apresentou maiores valores. FREITAS et al. (1988) observaram que a redução do teor de água do solo causou um decréscimo acentuado do número de grãos por espiga.

Para o peso do hectolitro, houve efeito significativo para a lâmina de água e das interações cultivar x manejo do solo e cultivar x lâmina de água (Tabela 3). No desdobramento cultivar x manejo do solo (Tabela 4B) e para valores de manejo do solo dentro de cultivar, verifica-se que houve efeito significativo apenas para a cultivar "IAC 24", onde o plantio direto proporcionou maior valor. Quanto a cultivar dentro de manejo, não houve diferença. No desdobramento cultivar x lâmina de água (Tabela 4C) e para valores de lâmina dentro de cultivar, verifica-se efeito significativo para as cultivares "IAC 24" e "BR 18”, onde a lâmina L2 (-0,05MPa) propiciou maior valor. Considerando cultivar dentro de lâmina, verifica-se que apenas a cultivar "BR 210" foi superior a "IAC 24" e "BR 18" para a lâmina L1 (-0,05MPa). O peso do hectolitro é um índice utilizado na comercialização de grãos, o qual tem aumento progressivo de preço quando 
Tabela 3 - Número de grãos por espiga, peso do hectolitro, peso de 100 grãos e rendimento de grãos na cultura do trigo, em função de cultivar, manejo do solo e lâmina de água.

\begin{tabular}{|c|c|c|c|c|c|}
\hline \multicolumn{2}{|c|}{ Tratamentos } & \multirow{2}{*}{$\begin{array}{c}\begin{array}{c}\text { Número de grãos } \\
\text { por espiga }^{[1]}\end{array} \\
33 \mathrm{a}\end{array}$} & \multirow{2}{*}{$\begin{array}{c}\begin{array}{c}\text { Peso do hectolitro } \\
\text { (kg) }\end{array} \\
78 \mathrm{a}\end{array}$} & \multirow{2}{*}{$\begin{array}{c}\begin{array}{c}\text { Peso de } 100 \text { grãos }^{[1]} \\
\text { (g) }\end{array} \\
3,59 \mathrm{~b}\end{array}$} & \multirow{2}{*}{$\frac{\begin{array}{c}\text { Rendimento } \\
\left(\mathrm{kg} \mathrm{ha}^{-1}\right)\end{array}}{2412 \mathrm{~b}}$} \\
\hline \multirow{3}{*}{ Cultivar } & "IAC 24" & & & & \\
\hline & “BRS 210” & 33 a & $80 \mathrm{a}$ & $4,02 \mathrm{a}$ & 2826 a \\
\hline & “BR 18” & $34 \mathrm{a}$ & 79 a & $4,06 \mathrm{a}$ & $2465 a b$ \\
\hline \multirow{2}{*}{ Manejo do solo } & Arado de Aivecas & $37 \mathrm{a}$ & $80 \mathrm{a}$ & 3,87 a & 2492 a \\
\hline & Plantio Direto & 33 a & 79 a & 3,92 a & 2643 a \\
\hline \multirow{2}{*}{ Lâmina de água } & L1 (-0,07 MPa) & $31 \mathrm{~b}$ & $78 \mathrm{~b}$ & $3,78 \mathrm{~b}$ & 1927 b \\
\hline & L2 (-0,05 MPa) & $34 \mathrm{a}$ & $80 \mathrm{a}$ & $4,01 \mathrm{a}$ & 3208 a \\
\hline \multirow{6}{*}{$\mathrm{F}^{[2]}$} & Cultivar (C) & $0,21 \mathrm{~ns}$ & $3,07 \mathrm{~ns}$ & $13,00^{* *}$ & $3,82^{*}$ \\
\hline & Manejo do Solo (M) & $0,56 \mathrm{~ns}$ & $1,60 \mathrm{~ns}$ & 0,34 ns & $1,29 \mathrm{~ns}$ \\
\hline & Lâmina de água (L) & $6,13^{*}$ & $7,64^{* *}$ & $7,44^{* *}$ & $92,65^{* *}$ \\
\hline & $(\mathrm{C} \times \mathrm{M})$ & $3,13 n s$ & $3,84^{*}$ & $0,04 \mathrm{~ns}$ & $4,19^{*}$ \\
\hline & $(\mathrm{C} \times \mathrm{L})$ & $0,90 \mathrm{~ns}$ & $6,58^{* *}$ & $7,87^{* *}$ & $3,46^{*}$ \\
\hline & $(\mathrm{M} \times \mathrm{L})$ & $11,42^{* *}$ & 0,19 ns & $0,29 \mathrm{~ns}$ & $0,53 \mathrm{~ns}$ \\
\hline $\mathrm{CV} \%$ & & 10 & 3 & 7 & 18 \\
\hline
\end{tabular}

${ }^{[1]}$ Médias seguidas da mesma letra, na coluna e para cada fator, não diferem estatisticamente entre si pelo teste de Tukey a $5 \%$ de probabilidade. ${ }^{[2] * * *}$ e ns são, respectivamente, significativo a $1 \%, 5 \%$ e não significativo pelo teste $\mathrm{F}$.

os valores se apresentam acima de $78 \mathrm{~kg} / \mathrm{hL}$, portanto, as cultivares apresentaram valores satisfatórios. FRIZZONE et al. (1996), na avaliação de várias lâminas de água, obtiveram peso do hectolitro superior nas lâminas maiores, ultrapassando o valor exigido para comercialização. O maior fornecimento de água favorece o enchimento de grãos, aumentando o peso do hectolitro.

Para o peso de 100 grãos, houve efeito em cultivar, lâmina de água e interação entre cultivar e lâmina de água (Tabela 3). No desdobramento cultivar x lâmina de água (Tabela 4 D) e para lâmina dentro de cultivar, observa-se efeito apenas para a cultivar "BR 18”, onde a lâmina L2 (-0,05MPa) proporcionou maior valor para 100 grãos. Quanto a cultivar dentro de lâmina, as cultivares "BRS 210” e "BR 18” foram superiores aos demais, respectivamente, para a lâmina L1 (0,07MPa) e L2 (-0,05MPa).ALBUQUERQUE et al.(1992) afirmaram que, para o peso de grãos, houve efeito positivo com o aumento da lâmina de água.

No rendimento de grãos, houve efeito de cultivar, lâmina de água e das interações cultivar $\mathrm{x}$ manejo de solo e cultivar x lâmina (Tabela 3). Para o desdobramento cultivar x manejo de solo (Tabela 4E) e manejo dentro de cultivar, verifica-se efeito apenas para a cultivar "BRS 210”, onde o plantio direto proporcionou maior valor. Quanto a cultivar dentro de manejo, "BRS 210" e "BR 18" foram superiores em relação a "IAC 24", no plantio direto. No arado de aivecas, não houve diferenças entre cultivares. $\mathrm{Na}$ interação cultivar x lâmina de água (Tabela 4 F) quanto aos valores de lâmina de água dentro de cultivar, verifica-se que a lâmina L2 (-0,05MPa) proporcionou maiores rendimentos para as três cultivares. Quanto a cultivar dentro de lâmina, as cultivares "IAC 24” e "BRS 210” apresentaram maior rendimento em relação à "BR 18” para a lâmina L2 (-0,05MPa). O rendimento de trigo pode variar de $2.500 \mathrm{~kg} \mathrm{ha}^{-1}$ a $3.800 \mathrm{~kg} \mathrm{ha}^{-1}$, dependendo da região de cultivo e da lâmina de água total. ESPINOZA et al. (1980), utilizando cultivares de trigo, obtiveram um consumo de $400 \mathrm{~mm}$ de água, chegando o rendimento de grãos próximo a $4.000 \mathrm{~kg} \mathrm{ha}^{-1}$.

\section{CONCLUSÕES}

As cultivares de trigo "IAC 24" e "BRS 210" apresentaram maior rendimento de grãos para o potencial mátrico do solo de -0,05MPa. O plantio direto proporcionou maiores rendimentos para as cultivares "BRS 210" e "BR 18” e, de modo geral, o plantio direto interferiu positivamente nas respostas das cultivares de trigo.

\section{AGRADECIMENTOS}

Os autores agradecem à Fundação de Apoio à Pesquisa do Estado de São Paulo e à EMBRAPA- Agropecuária Oeste, pelo apoio material. 
Tabela 4 - Interação entre causas de variação ${ }^{[1]}$ para os componentes produtivos.

\begin{tabular}{|c|c|c|c|}
\hline \multirow[t]{2}{*}{ Manejo do solo } & \multicolumn{3}{|c|}{ 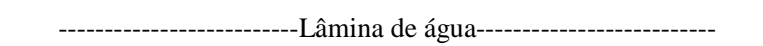 } \\
\hline & \multicolumn{2}{|c|}{ L1(-0,07 MPa) } & L2 (-0,05 MPa) \\
\hline Arado de Aivecas & \multicolumn{2}{|l|}{29,75 bB } & 35,63 aA \\
\hline Plantio Direto & $33,90 \mathrm{aA}$ & & 32,99 aA \\
\hline \multirow[t]{2}{*}{ Manejo do solo } & \multicolumn{3}{|c|}{ - } \\
\hline & “IAC 24” & “BRS 210” & “BR 18” \\
\hline Arado de Aivecas & 79,98 aA & 81,60 aA & 77,69 aA \\
\hline Plantio Direto & $76,96 \mathrm{bA}$ & 79,65 aA & $79,72 \mathrm{aA}$ \\
\hline \multirow{2}{*}{ Lâmina de água } & \multicolumn{3}{|c|}{ - } \\
\hline & "IAC 24" & "BRS 210” & "BR 18" \\
\hline L1 (-0,07 MPa) & $76,56 \mathrm{bB}$ & 81,57 aA & $76,43 \mathrm{bB}$ \\
\hline L2 (-0,05 MPa) & 80,38 aA & 79,73 aA & $80,98 \mathrm{aA}$ \\
\hline 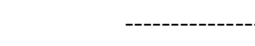 & na de água e cultivar, & so de 100 grã & 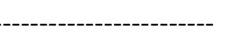 \\
\hline \multirow[t]{2}{*}{ Lâmina de água } & \multicolumn{3}{|c|}{ - } \\
\hline & “IAC 24” & “BRS 210” & “BR 18” \\
\hline L1 (-0,07 MPa) & $3,52 \mathrm{aB}$ & $4,09 \mathrm{aA}$ & $3,73 \mathrm{bB}$ \\
\hline L2 (-0,05 MPa) & $3,66 \mathrm{aB}$ & $3,96 \mathrm{aB}$ & $4,40 \mathrm{aA}$ \\
\hline \multirow{2}{*}{ Manejo do solo } & \multicolumn{3}{|c|}{ - } \\
\hline & "IAC 24” & “BRS 210” & “BR 18” \\
\hline Arado de Aivecas & $2600 \mathrm{aA}$ & 2559 bA & $2317 \mathrm{aA}$ \\
\hline Plantio Direto & $2224 \mathrm{aB}$ & 3094 aA & $2612 \mathrm{aA}$ \\
\hline \multirow[t]{2}{*}{ Lâmina de água } & \multicolumn{3}{|c|}{ ( } \\
\hline & “IAC 24” & “BRS 210” & “BR 18” \\
\hline L1 (-0,07 MPa) & 1640 bA & 2070 bA & $2072 \mathrm{bA}$ \\
\hline L2 (-0,05 MPa) & 3184 aA & 3583 aA & $2857 \mathrm{aB}$ \\
\hline
\end{tabular}

${ }^{[1]}$ Médias seguidas da mesma letra, minúscula na coluna e maiúscula na linha, para cada fator, não diferem entre si pelo teste de Tukey a 5\% de probabilidade.

\section{REFERÊNCIAS}

ABRÃO, P.U.R. et al. Efeitos de sistema de preparo do solo sobre características de um Latossolo Roxo Distrófico. Revista Brasileira de Ciência do Solo, v.3, p.169-172, 1979.

ALBUQUERQUE, J.A. et al. Rotação de culturas e sistemas de manejo do solo: efeito sobre a forma da estrutura do solo ao final de sete anos. Revista Brasileira de Ciência do Solo, v.19, p.115-119, 1995.

ALBUQUERQUE, P.E.P. et al. Irrigação de trigo em solo sob vegetação de cerrado, em Minas Gerais. Pesquisa Agropecuária Brasileira, v.27, n.6, p.935-948, 1992.

CANNEL, R.Q.; FINNEY, F.R. Effects of direct drilling and reduced cultivation on soil conditions for root growth. Outlook on Agriculture, v.7, n.4, p.184-189, 1973.

DEMATTÊ, J.L.I. Levantamento detalhado dos solos do “Campus Experimental de Ilha Solteira”. Piracicaba: ESALQ/USP, 1980. 44p.
ESPINOZA, W. et al. Irrigação de trigo em solo de cerrado. Pesquisa Agropecuária Brasileira, v.15, n.1, p.107-115, 1980.

FARIA, R.T.; OLITTA, A.F.L. Lâmina de irrigação na cultura do trigo utilizando o sistema de "aspersão em linha". Pesquisa Agropecuária Brasileira, v.22, n.9/10, p.999-1008, 1987.

FREITAS, J.G. et al. Trigo: real e na produção e seus componentes. Bragantia, v.44, n.2, p.515-530, 1988.

FREITAS, P.I. Manejo físico do solo. In: SIMPÓSIO SOBRE MANEJO E CONSERVAÇÃO DO SOLO NO CERRADO, 1990, Goiânia. Anais... Campinas: Fund. Cargill, 1992. p.117-139.

FRIZZONE, J.A. et al. Efeito de diferentes níveis de irrigação e adubação nitrogenada sobre componentes de produtividade da cultura de trigo. Pesquisa Agropecuária Brasileira, v.31, n.6, p.425-434, 1996.

FUMIS, T.F. et al. Análise de crescimento em cultivares de trigo (Triticum aestivum L.) submetidos a déficits hídricos, na região de Bauru-SP. Irriga, v.2, n.3, p. 101-114, 1997.

Ciência Rural, v.38, n.4, jul, 2008. 
GUERRA, A.F. et al. Tensão de água no solo: um critério viável para a irrigação do trigo na região do cerrado. Pesquisa Agropecuária Brasileira, v.29, n.4, p.631-636, 1994.

KLAR, A.E.; DENADAI, I.A.M. Resistência à seca em cultivares de trigo: qualidade e rendimento dos grãos e medições fisiológicas. Irriga, v.1, n.2, p.1-25, 1996.

LAL, R. No-tillage effects on soil conditions and crop response on an Alfisol in Southern Nigeria. America Society Agronomic, 1975. 38p. Abstr.

RAIJ, B. van; QUAGGIO, J.A. Métodos de análise de solo para fins de fertilidade. Campinas: Instituto Agronômico, 1983. 31p. (Boletim técnico, 81).

SOUZA, Z.M. Propriedades físicas e químicas de um Latossolo Vermelho-Escuro de Selviria-MS., solos diferentes: usos e manejos. 2000. 127f. Dissertacão (Mestrado em Agronomia) - Faculdade de Engenharia de Ilha Solteira, Universidade Estadual Paulista, Ilha Solteira.

SOUZA, P.G. Novas cultivares. "BR 18-Terena”: cultivar de trigo para o Brasil. Pesquisa Agropecuária Brasileira, v.37, n.7, p.1039-1043, 2002.

SOUZA, R.A.R. Comportamento de cultivares de arroz de terras altas em função do preparo do solo e irrigação por aspersão, em latossolo vermelho de cerrado. 2003. 68f. Dissertação (Mestrado em Agronomia) - Faculdade de Engenharia de Ilha Solteira, Universidade Estadual Paulista, Ilha Solteira.

STONE, L.F.; MOREIRA J.A.A. Efeitos de sistema de preparo do solo no uso da água e na produtividade do feijoeiro. Pesquisa Agropecuária Brasileira, v.35, n.4, p.835-841, 2000.

VIEIRA, M.J. Tecnologia poupadoras de insumos. 1. Cultivo mínimo comparado a outros sistemas. 1.1. Efeitos no solo e na planta. In: SIMPÓSIO SOBRE ENERGIA NA AGRICULTURA, Tecnologia poupadoras de Insumos, integração..., 1984, Jaboticabal. Anais... Jaboticabal: FCAC, 1985. p.32-54.

VIEIRA, M.J. Tillage practices and soil physical degradation in the wheat cropping systems of the warmer areas of latin america. Wheat for the nontraditional, warm areas Mexico. In: A PROCEEDING OF THE INTERNATIONAL CONFERENCE, 1991, Foz do Iguaçu. Conference... Foz do Iguaçu: s.n., 1991. p.242-256.

VIEIRA, M.J. et al. Perdas pro erosão em diferentes sistemas de preparo do solo para a cultura da soja (Glycine Max (L.) Merr.) em condições de chuvas simulada. Revista Brasileira de Ciência do Solo, v.2, n.3, p.209-214, 1978. 